Eduardo C. Yap, MD 1,2

'Belo Medical Group

2Department of ENT

Metropolitan Medical Center
Correspondence: Dr. Eduardo C. Yap

Unit 3, 28 Times St., West Triangle, Quezon City 1104 Philippines

Phone: (632) 82541111

Email: edcyap88@gmail.com

The author declares that this represents original material that is not being considered for publication elsewhere in full or in part, in print or electronic media; that the manuscript has been read and approved by the author, that the requirements for authorship have been met by the author, and that the author believes that the manuscript represents honest work.

Disclosures: The author signed a disclosure that there are no financial or other (including personal) relationships, intellectual passion, political or religious beliefs, and institutional affiliations that might lead to a conflict of interest.

\section{Understanding the Use of Polycaprolactone in East Asian Structural Rhinoplasty: Questions and Answers}

Keywords: Polycaprolactone; PCL mesh; structural rhinoplasty; extended spreader graft; septal extension graft; septoplasty

Surgery as an art in rhinoplasty involves grafting techniques wherein materials (usually autologous) are taken from the septum and supplemented by conchal cartilage. However, not all noses have adequate cartilage material. The quest for materials as possible replacement for human tissue have led to invention of synthetic (e.g. silicone, e-PTFE, porous polyethelene) and non-synthetic products (e.g. processed homograft and xenograft). In this era of advanced medical science, tissue engineering has started the use polycaprolactone $(\mathrm{PCL})$ as a template and scaffold for tissue growth. Because of this characteristic feature, PCL as a mesh has a significant role in structural rhinoplasty.

\section{What is structural rhinoplasty?}

The surgical goal of rhinoplasty is to achieve functional improvement in breathing and aesthetic overall look, most notably the tip. The tip is determined by the final shape of the lower cartilage in its proper location - - but since the lower cartilage is a floating structure supported only by fibrous tissue and ligaments, there is a high incidence of tip drooping post op. So, the idea of structured rhinoplasty was conceptualized in 1997 by Dr. Byrd and popularized by Dr. Toriumi. ${ }^{1,2} \mathrm{~A}$ piece of central septum is harvested and fashioned as an extension of the caudal margin of the septum. This is called a septal extension graft (SEG) and the lower cartilage is sutured to the caudal margin of the SEG for better control of the tip. Since then, the technique has been the main workhorse support graft for the tip. ${ }^{3}$ (Figure 1)

\section{Why is structural rhinoplasty needed in East Asian noses?}

East Asian noses, particularly Southeast Asian noses are usually short and small, with low dorsum and upturned bulbous nose. Tremendous strength in the design of the structural support with its foundation base at the caudal septum should be achieved in order to elongate the nose, counter rotate and project the tip. (Figure 2) This is made possible by using the central harvested cartilage as a SEG attached to the residual strong dorsal and caudal strut. ${ }^{4}$ (Figure 3)

\section{Why is it that SEG alone fails in achieving the desired result?}

It was noted that the septum of Asian noses is weak and small. Using the harvested septal 


\section{PRACTICE PEARLS}

cartilage as a SEG alone may not be strong enough to fix the tip in a new vector of projection. Usually, there is a need to spare a smaller piece of the harvested septum as an extended spreader graft (ESG) to counteract the bending and collapse of the SEG. Therefore, the foundation system is a usually a combination of SEG and ESG fashioned in a new vector for tip counter rotation and projection. ${ }^{5}$

Since the introduction of the concept of extending the caudal margin of the septum, many varieties of SEG evolved but are mainly of 2 types: side-to-side SEG and end-to-end SEG. The side-to-side SEG is attachment of the SEG to either side of the caudal strut of the septum while the end-to-end SEG is attachment of the SEG directly at the caudal margin of the caudal strut held by bilateral ESG. ${ }^{6}$ (Figure 4 and 5)

\section{What should be done if the harvested septum is weak and small?}

Sometimes the septum is small and soft with some inherent deviation leading to a dilemma on to how to design an adequate SEG and ESG. Folded conchal cartilage may be used as extension graft of a SEG, however since conchal cartilage is weak, it may droop or deviate. Although costal cartilage is the best graft material, it is not popular because of the high cost and morbidity of the procedure, and other non-autologous materials may be used instead e.g. processed homograft, xenograft and synthetic products like the non-absorbable porous polyethylene and absorbable polycaprolactone ( $\mathrm{PCL})$. Of all the non-autologous materials, $\mathrm{PCL}$ seems to be the more favorable material because it has properties similar to septum, and it is resorbable in 2 years.

\section{What is polycaprolactone?}

Polycaprolactone (PCL) is a biocompatible and biodegradable synthetic polyester polymer that has been extensively used as 3D scaffold in bone tissue, cartilage and mesenchymal tissue engineering. PCL resorbs in 2-3 years depending on thickness after which new surrounding in-growth tissue structures mature. Whatever tissue is placed beside the PCL during the healing process will be the same tissue until total resorption. Recent applications include scaffolds for bone defects in craniomaxillofacial surgery and fillers/threads in aesthetic facial rejuvenation.?

Polycaprolactone is 3D printed and can be made accordingly to the shape desired. The dimension and strength can be varied as requested. The product commercial availability in the late quarter of 2018 made its role very useful in septoplasty and rhinoplasty because its physical properties are similar to septal cartilage. The usual dimension is $10 \mathrm{~mm} \times 40 \mathrm{~mm} \times 1 \mathrm{~mm}$. (Figure 6) The PCL mesh can be cut easily by blade or scissors and sutured to surrounding tissues. The role of $\mathrm{PCL}$

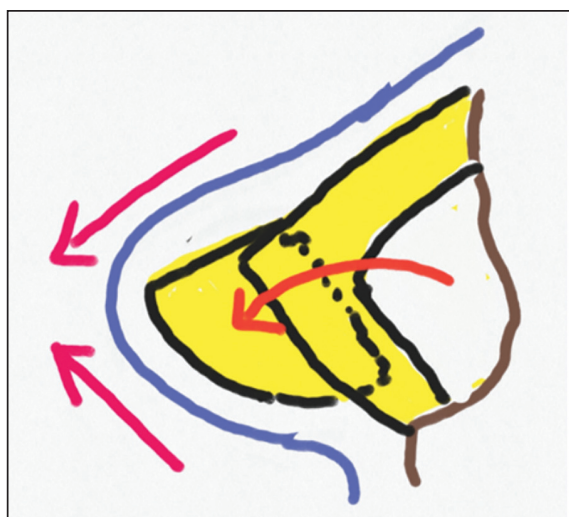

Figure 1. The Septal Extension Graft (SEG). The usual technique to lengthen the nose and counter-rotate the tip is the use of central harvested septum and fashioned into a support graft. Commonly used technique is the septal extension graft.

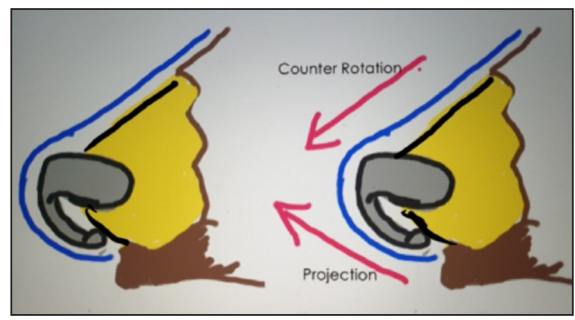

Figure 2. The aim in Asian Rhinoplasty is counter rotation and projection of the tip.

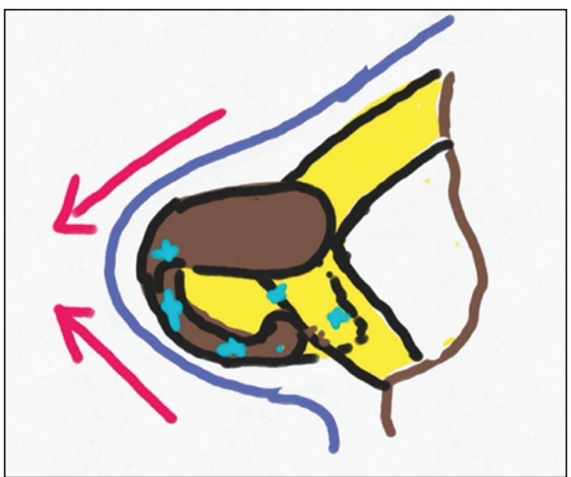

Figure 3. The final concept of counter-rotation and projection of the tip. The lower cartilage is sutured to the caudal edge of the SEG.

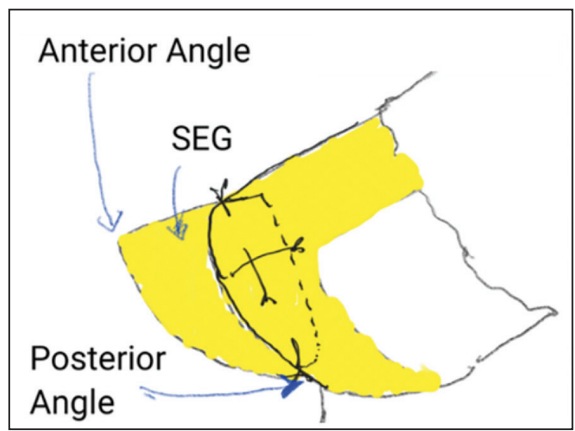

Figure 4. Side-to-side SEG. This requires a strong dorsal and caudal strut. This technique may sometimes lead to deviation at the junction of suture fixation of SEG and caudal strut causing obstruction and twisting of the tip. 


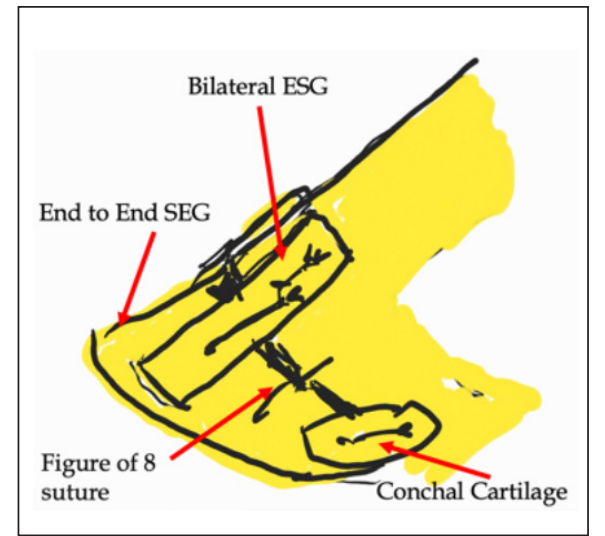

Figure 5. . End-to-end SEG. This technique assures a midline structure. The bilateral extended spreader graft (ESG) stabilizes the end-to-end SEG. The ESG not only straightens, counterrotates and strengthens the dorsal strut but also widens the internal valve. It is also necessary to put spare septal or conchal cartilage at the posterior part of the end-to-end SEG for further stabilization. This technique assures a midline support. Deviation and obstruction are seldom encountered.

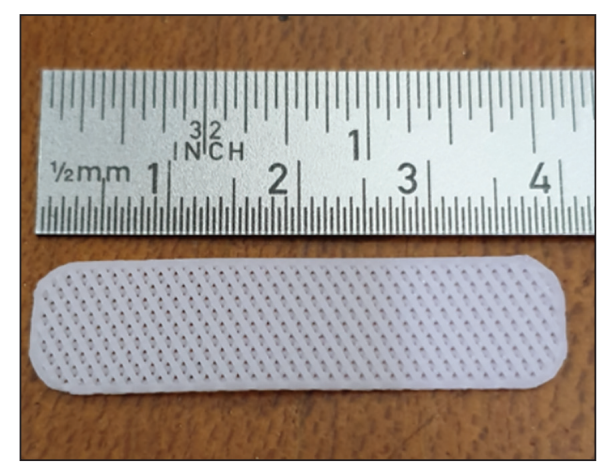

Figure 6. A sample PCL mesh $10 \mathrm{~mm} \times 40 \mathrm{~mm} \times 1 \mathrm{~mm}$

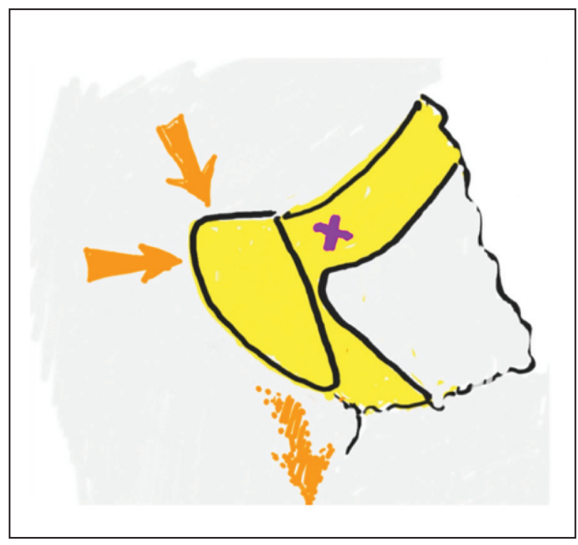

Figure 7. Weak dorsal strut. In some cases of support grafting the dorsal strut collapses or is bent because of the pressure and tension of the lower cartilage and skin/soft tissue envelope (SSTE) during closure thereby causing deviation, obstruction and twisting/drooping of the tip. is initially as a scaffold for strength in support and later as a template for tissue adhesion, migration and proliferation. It is advisable that the surrounding tissues are cartilage so that after 2-3 years when the $\mathrm{PCL}$ is totally resorbed it will be replaced with the ingrown cartilage. ${ }^{8}$ Polycaprolactone should not be used for pressure or weight bearing purposes because it may extrude or break during the process of healing.

\section{How do you use $\mathrm{PCL}$ in structural rhinoplasty?}

The principle in structural grafting in Asian rhinoplasty is to modify the nasal tip to a more counter rotated and projected position. The lower cartilage which determines the tip is sutured to a structure which is firmly fixed to the septum. The usual technique is to make the inherent dorsal and caudal struts (after harvest of central septum) stronger and more extended. The lower cartilage is then sutured and fixed to the caudal margin of the extended strut system for a new projected and counter rotated tip.

The approach is an open rhinoplasty with dissection of membranous septum to expose the caudal edge of cartilaginous septum. The septum is approached anteriorly in a subperichondrial plane; the dissection can be unilateral or bilateral. The central cartilage is harvested leaving a 10$12 \mathrm{~mm}$ dorsal and caudal strut. There are some instances that harvested septal cartilage may be inadequate because of inherent small size and weakness, and likewise the remaining dorsal and caudal struts are weak or deviated. (Figure 7) In these instances, $\mathrm{PCL}$ is used as a unilateral or bilateral extended spreader graft (ESG) and septal extension graft (SEG).

\section{Why is PCL used as ESG and SEG in Structural Rhinoplasty?}

The ESG lengthens, straightens and strengthens the dorsal strut while the SEG extends the whole strut system for tip support..$^{10}$ Because of the stiff nature of the PCL mesh, a unilateral placement of ESG is good enough to support a SEG which is designed as an end-to-end attachment so the vector of healing contraction force is in the midline, minimizing chances of extrusion in mucosa. ${ }^{11,12}$ (Figure 8) Any deviation in the caudal strut can be corrected with a batten graft from the harvested septum. ${ }^{13}$ The rest of the PCL can be covered with remaining septal cartilages and conchal cartilages. Finally, a folded conchal cartilage is sutured at the caudal margin of the SEG in order to protect against erosion to mucosa and columellar skin. (Figure 9 and 10)

This type of PCL structural grafting addresses almost all types of deviation and weakness of the septal strut. The end-to-end SEG assures a midline structure too. The whole system will not deviate because the SEG is held by ESG deep from the dorsal septum. (Figure 8) 

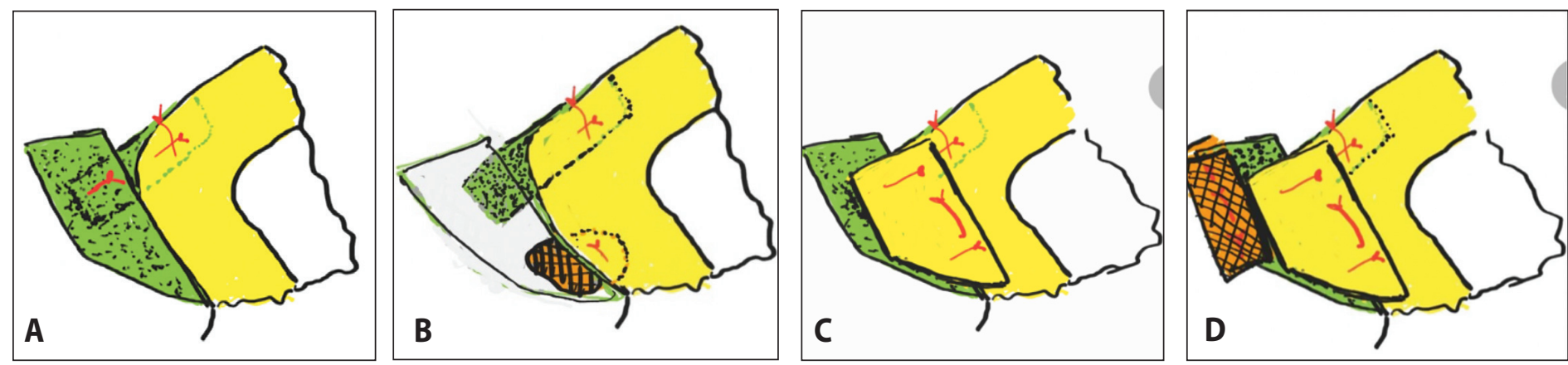

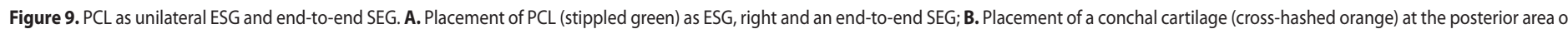

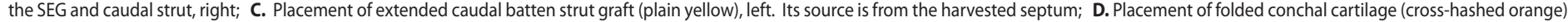
at the caudal margin of the SEG. Fixation suture done using PDS ${ }^{\oplus} 5-0$. Majority of PCL including the ESG should be covered with cartilage for adhesion and migration of cartilage tissue.

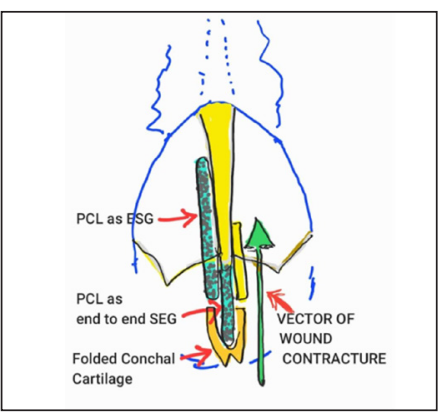

Figure 8. PCL used as unilateral ESG $(R$, stippled green) and end-to-end SEG (midline, stippled green). A piece of septal cartilage is used as caudal batten graft ( $L$, plain yellow). A folded conchal cartilage (midline, plain yellow) is attached at the caudal margin of the PCL. Note the vector of wound contracture is midline towards the septum. This design of structural grafting will not cause extrusion of the PCL nor cause deviation or collapse of the septal struts.
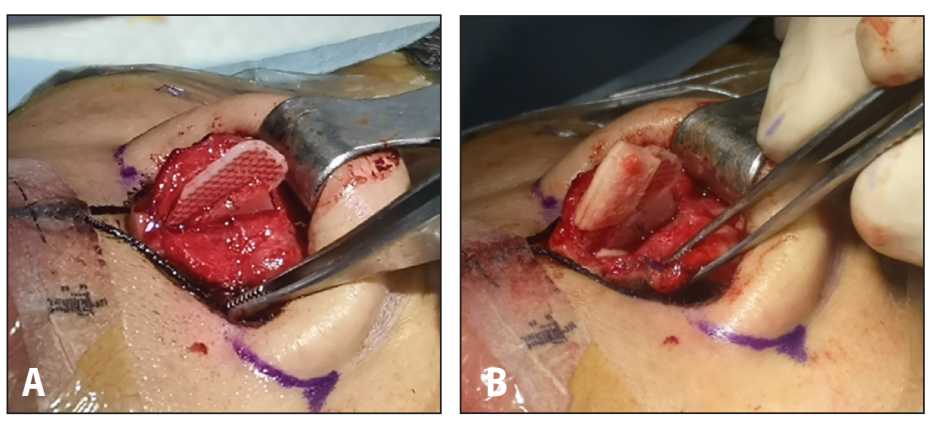

Figure 10. Sample intraoperative photo of PCL as end-to-end SEG. A. PCL as end-to-end SEG and septal cartilage as extended caudal batten graft, left. Not shown is the PCL as ESG on the right. The PCL-ESG and septum-extended caudal batten graft hold the end-to-end SEG well; B. Folded conchal cartilage is utilized as coverage of the caudal margin of the SEG in order to prevent erosion to skin and mucosa. The folded conchal cartilage is where the lower cartilage is fixed for the final nasal framework.

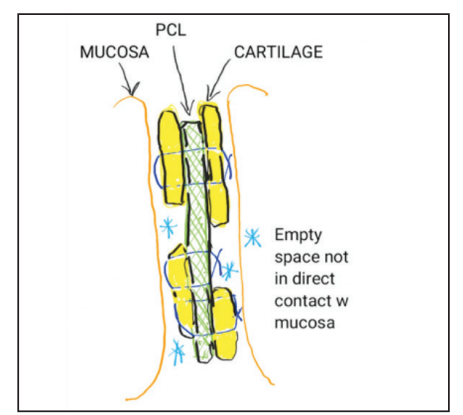

Figure 11. Schematic diagram of PCL covered with cartilages to allow adhesion, migration and proliferation of cartilage tissue. Note that sutures are all submucosal. Notice too that the mucosa is elevated from PCL because of cartilage placement. Since $\mathrm{PCL}$ will be totally resorbed in 2-3 years, it is advisable to avoid direct contact of mucosa to PCL. This is to avoid chances of erosion and subsequent extrusion.

\section{Can one use PCL solely like a septum?}

Unfortunately, PCL should not be used solely as a graft similar to a septum. In the early phase, PCL should be treated as a scaffold in correction of deviation and strengthening a weak cartilage. In the late phase, PCL acts as a mesh or template for ingrowth of tissue. Therefore, it is highly recommended to cover the mesh with cartilages even in patches to allow cartilage cells to integrate. It is advised also to avoid direct contact of $\mathrm{PCL}$ to mucosa. ${ }^{8}$ (Figure 11)

\section{Will the use of PCL shorten the operating time?}

Using PCL in structural rhinoplasty prolongs the operating time because the surgeon has to plan and imagine the fate of the future of the PCL grafts since PCL will be hydrolyzed and resorbed in 2 years. Therefore, majority of PCL should be covered with cartilages to allow tissue ingrowth in order to provide strength in the future. This will assure longevity of the support graft system of the nose. (Figure 12)
In summary, PCL mesh is a good material for use in structural rhinoplasty where the septum is weak or small. It is absorbable and easy to use because its physical properties are similar to septum. In the early phase, PCL acts as a scaffold to correct deviation and weakness of the septum, while in the late phase, it acts as a template for tissue ingrowth. Therefore, cartilage should cover the majority of the PCL especially at key areas where the future extended dorsal and caudal struts will be located. (Figure 13) 


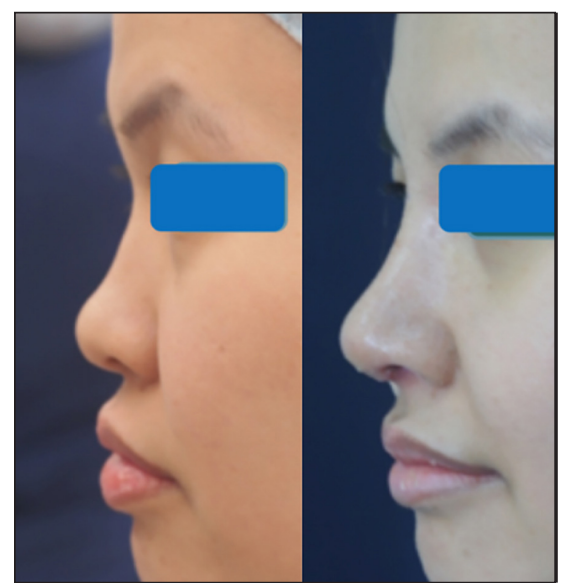

Figure 12. Pre-op (L) and post-op (R) photos. Pre-operative and post-operative photos show a remarkable change of the nose. The tip is counter rotated and well projected. The premaxilla is fuller. Structural rhinoplasty assures longevity of results.
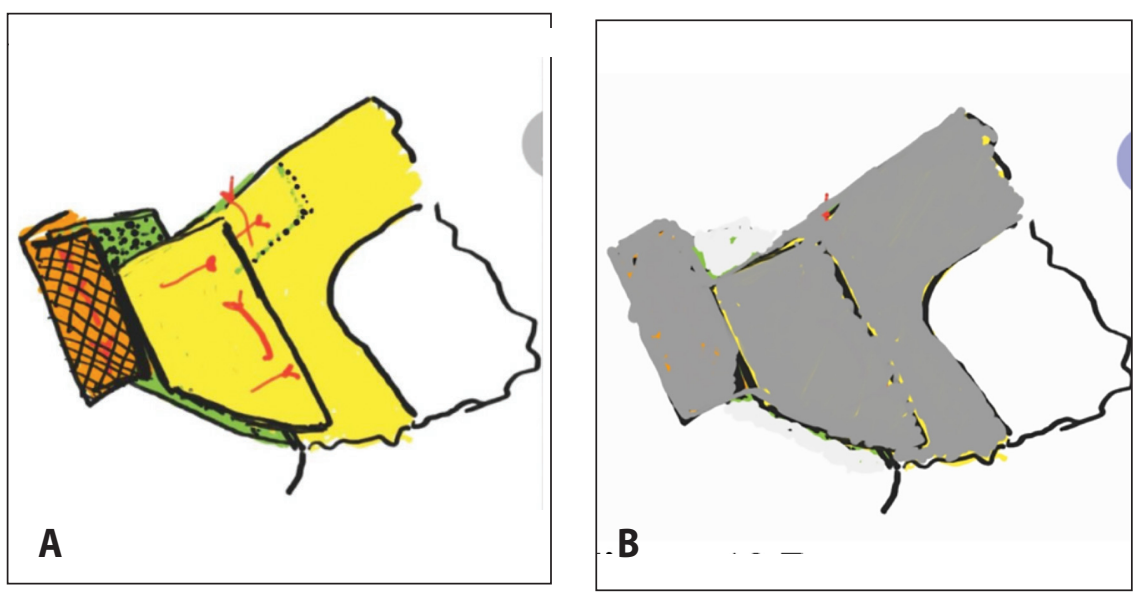

Figure 13. PCL role in structural rhinoplasty. A. In its initial phase, $\mathrm{PCL}$ acts as a scaffold which provides strength; $\mathbf{B}$. In the late phase, $\mathrm{PCL}$ acts as template for tissue ingrowth. Therefore, it is essential that the tissue surrounding the $\mathrm{PCL}$ should be cartilage in order for the support system to sustain strength.

\section{REFERENCES}

1. Byrd HS, Andochick S, Copit S, Walton KG. Septal extension grafts: a method of controlling tip projection shape. Plast Reconstr Surg. 1997 Sep;100(4):999-1010. DOI: 10.1097/00006534199709001-00026; PubMed PMID: 9290671.

2. Toriumi DM. Structure approach in rhinoplasty. Facial Plast Surg Clin North Am. 2005 Feb;13(1):93-113. DOI: 10.1016/j.fsc.2004.07.004; PubMed PMID: 15519931.

3. Rohrich RJ, Durand PD, Dayan E. Changing role of septal extension versus columellar grafts in modern rhinoplasty. Plast Reconstr Surg. 2020 May;145(5): 927e-931e. DOI: 10.1097/ PRS.0000000000006730; PubMed PMID: 32332531.

4. Toriumi DM. Discussion: septum-based nasal tip plasty: a comparative study between septal extension graft and double-layered conchal cartilage extension graft. Plast Reconstr Surg. 2018 Jan;141(1):57-58. DOI: 10.1097/PRS.0000000000004125; PubMed PMID: 29280861.

5. Chen YY, Kim SA, Jang YJ. Centering a deviated nose by caudal septal extension graft and unilaterally extended spreader grafts. Ann Otol Rhinol Laryngol. 2020 May;129(5):448-455. DOI: 10.1177/0003489419894617; PubMed PMID: 31822124.

6. Kim MH, Choi JH, Kim MS, Kim SK, Lee KC. An introduction to the septal extension graft. Arch Plast Surg. 2014 Jan; 41(1): 29-34. DOI: 10.5999/aps.2014.41.1.29; PubMed PMID: 24511491; PubMed Central PMCID: PMC3915152.

7. Christen MO, Vercesi F. Polycaprolactone: How a well-known and futuristic polymer has become an innovative collagen-stimulator in esthetics. Clin Cosmet Investig Dermatol. 2020 Jan 20;13;31-48. DOI: 10.2147/CCID.S229054; PubMed PMID: 32161484; PubMed Central PMCID: PMC7065466.
8. Yap E. Techniques in the safe use of polycaprolactone in structural rhinoplasty. Philipp $J$ Otolaryngol Head Neck Surg. 2020 May;35(1): 66-70. DOI: 10.32412/pjohns.v35i1.1267.

9. Choi JY, Kang IG, Javidnia H, Sykes JM. Complications of septal extension grafts in Asian patients. JAMA Facial Plast Surg. 2014 May-Jun; 16(3):169-75 DOI: 10.1001/jamafacial.2013.2379; PubMed PMID: 24526131.

10. Palacín JM, Bravo FG, Zeky R, Schwarze H. Controlling nasal length with extended spreader grafts: a reliable technique in primary rhinoplasty. Aesthetic Plast Surg. 2007 Nov-Dec;31(6):645-50 DOI: 10.1007/s00266-007-0065-8; PubMed PMID: 17876658.

11. Kim DH, Yun WS, Shim JH, Park KH, Choi D, Park M. Clinical application of 3-dimensional printing technology for patients with nasal septal deformities: a multicenter study. JAMA Otolaryngol Head Neck Surg. 2018 Dec 1;144 (12): 1145-1152. DOI: 10.1001/jamaoto.2018.2054; PubMed PMID: 30326042; PubMed Central PMCID: PMC6583092.

12. Park YJ, Cha JH, Bang SI, Kim SY. Clinical application of three-dimensionally printed biomaterial polycaprolactone (PCL) in augmentation rhinoplasty. Aesthetic Plat Surg. 2019 April; 43(2):437446. DOI: 10.1007/200266-018-1280-1; PubMed PMID: 30498936.

13. Wee JH, Lee JE, Cho SW, Jin HR. Septal Batten Graft to Correct Cartilaginous Deformities in Endonasal Septoplasty. Arch Otolaryngol Head Neck Surg. 2012 May; 138(5): 457-461. DOI: 10.1001/archoto.2012.650; PubMed PMID: 22652943. 